\title{
Intestinal endometriosis combined with colorectal cancer: a case series
}

\author{
Masatsugu Ishii1", Masashi Yamamoto', Keitaro Tanaka', Mitsuhiro Asakuma', Shinsuke Masubuchi', \\ Hiroki Hamamoto ${ }^{1}$, Hiroshi Akutagawa ${ }^{3}$, Yutaro Egashira ${ }^{3}$, Yoshinobu Hirose ${ }^{3}$, Junji Okuda ${ }^{2}$ \\ and Kazuhisa Uchiyama'
}

\begin{abstract}
Background: Intestinal endometriosis is a common benign disease among menstruating women that affects the intestinal tract.

Case presentation: This case report presents seven Japanese cases of intestinal endometriosis with colorectal cancer treated by laparoscopic surgery. Five of the seven cases reported here are women presenting with bowel obstruction due to colorectal endometriosis with colorectal cancer. It can be confused with serious lesions such as advanced colorectal cancer with peritoneal involvement or invasion of adjacent organs (T4).

Conclusions: Therefore, we should consider the probability that the cause of bowel obstruction is not T4 but intestinal endometriosis. For surgical treatment, we recommend laparoscopic surgery for colorectal resection because of its benefits of differential diagnosis of T4, preserving fertility, and preventing excessive surgical stress. We performed laparoscopic resection in seven patients with intestinal endometriosis and colorectal cancer. These cases demonstrate the difficulty of establishing a differential diagnosis of intestinal endometriosis with colorectal cancer from T4.
\end{abstract}

Keywords: Intestinal endometriosis, Colorectal cancer, Laparoscopic surgery

\section{Background}

Intestinal endometriosis is histologically defined as the presence of endometrial glands in the intestinal tract [1-4]. This condition may cause dysmenorrhea, chronic pelvic pain, infertility, dyspareunia, and urinary and intestinal disorders during menstrual flow [1-4]. It is a common benign disease among menstruating women. Diagnostic suspicion of intestinal endometriosis is mainly clinical, based on the aforementioned signs and symptoms caused by the disorder. However, the symptoms are rare and the lack of pathognomonic signs makes the diagnosis difficult. Even during intervention we may confuse intestinal endometriosis with T4 colorectal cancer [5]. Complete removal of all lesions should be performed. A laparoscopic surgical procedure is feasible and effective for making a differential diagnosis of colorectal endometriosis from other malignancies, and is associated with improvements

\footnotetext{
* Correspondence: sur151@osaka-med.ac.jp

${ }^{1}$ Departments of General and Gastroenterological Surgery, Osaka Medical College, Osaka, Japan

Full list of author information is available at the end of the article
}

of quality of life and renewed fertility. In this report, we present seven cases in which intestinal endometriosis coexists with colorectal cancer.

\section{Case presentation}

We present seven patients with diagnosed intestinal endometriosis and colorectal cancer. There were 25 patients diagnosed with intestinal endometriosis from 1988 to 2010 at the Departments of General and Gastroenterological Surgery, Osaka Medical College. The detailed clinical results for each of the seven Japanese patients are summarized in Table 1 . The average age of the patients was 58.8 years (range $51-68$ years), and body mass index (BMI) was 21.5 (range $17.2-25.5 \mathrm{~kg} / \mathrm{m}^{2}$ ). All patients were interviewed preoperatively about symptoms, abdominal pain, genital bleeding, melena, dyschezia, and fecal occult blood positivity. There were two nulliparae and five multiparae among our cases. Colonoscopy was performed in seven patients, which revealed an ulcerofungating mass in five patients and a polypoid mass in two patients. A previous colonoscopic biopsy did not reveal 
Table 1 Clinical characteristics of seven patients with intestinal endometriosis and colorectal cancer

\begin{tabular}{lllllll}
\hline & Age (y) & BMI & Parity & ASA & Symptoms and signs & EM history \\
\hline 1 & 53 & 17.2 & 0 & 1 & Genital bleeding & + \\
2 & 64 & 25.5 & 1 & 1 & Melaena & - \\
3 & 51 & 22.9 & 1 & 1 & Faecal occult blood & - \\
4 & 57 & 22.4 & 3 & 1 & Faecal occult blood & + \\
5 & 68 & 20.7 & 0 & 1 & Melaena, abdominal pain & - \\
6 & 61 & 20.0 & 2 & 1 & Faecal occult blood & - \\
7 & 58 & 22.4 & 1 & 1 & Melaena, abdominal pain & - \\
\hline
\end{tabular}

$B M I$ body mass index, EM endometriosis, ASA American Society of Anesthesiologists

endometriosis but revealed malignancy except for cases 1 and 4. A computed tomography (CT) scan was also performed in all patients, and showed limited thickening of the wall of the intestine. Case 1 was diagnosed as having gastrointestinal stromal tumor (GIST). For the other patients, intestinal endometriosis was not diagnosed by preoperative examination; however, colorectal cancer was diagnosed. The primary location was the sigmoid colon in two patients, rectosigmoid colon in three patients, ascending colon in one patient, and cecum in one patient. Laparoscopic surgery was performed in all patients. In case 7, the main tumor had severe adhesions with the uterus and at the anal side of this tumor, a hard mass was observed at the serosal side of the rectum. However, the main tumor did not directly invade the uterus, so we performed laparoscopic low anterior resection with only adhesiolysis of the main tumor and uterus. Intraoperative rapid diagnosis revealed that it was intestinal endometriosis, so we could preserve the uterus. The average operative time was 190 minutes and volume of blood loss was $260 \mathrm{ml}$ (Table 2). In case 1, after the Hartmann procedure, a pelvic abscess was recognized by $\mathrm{CT}$ image. Case 3 had postoperative surgical site infection. Finally, all surgical resectional specimens indicated endometriosis according to final pathology reports (Table 3). Lung metastasis was present in two patients. Liver metastasis was present in two patients. Lymphovascular involvement by adenocarcinoma was present in five patients. The average number of dissected lymph nodes was 16 (range 7-28). Lymph node metastasis by adenocarcinoma was present in four patients and endometriosis was present in two patients.

\section{Discussion}

Endometriosis is histologically defined as the presence of endometrial glands and stroma outside the uterus [1-4]. It is a common benign disease among menstruating women [1-4]. The frequency of intestinal endometriosis is estimated to be approximately $3-34 \%$ of endometriosis [14]. Endometriosis is estimated to affect the intestinal tract in $15-37 \%$ of patients with pelvic endometriosis [5-7]. Many theories regarding the pathogenesis of this benign gynecological disease have been proposed. The most widely accepted theory proposes retrograde menstruation and subsequent implantation of regurgitated endometrial cells on the peritoneum and pelvic viscera, which appears to be facilitated by alterations in cell-mediated and humoral immunity [5]. This pathology occurs in women of childbearing age and can be located in various anatomic sites including the peritoneum, ovary, fallopian tubes, cervix, vagina, vulva, rectovaginal septum, uterosacral ligaments, rectosigmoid bowel, bladder, uterus, and skin [5]. Intestinal endometriosis often presents as bowel obstruction due to a submucosal tumor or luminal stenosis because endometrial tissue usually involves the outer walls of the intestinal tract such as the serosal or submucosal layer. In that case, preoperative diagnosis of intestinal endometriosis is very difficult despite the use of CT or magnetic resonance imaging (MRI), and it is important to differentially diagnose intestinal endometriosis from advanced colorectal cancer such as invasion of adjacent organs (T4) [8].

In general, in almost all cases, intestinal endometriosis is diagnosed by histological findings after surgical resection [5]. Actually, in our series, there were no cases of preoperatively diagnosed intestinal endometriosis.

Operation is the basic treatment when treatment is needed for intestinal endometriosis. For surgical treatment of intestinal endometriosis, early detection, resection of endometrial tissue, and relief of symptoms are important.

Table 2 Intraoperative and postoperative data after laparoscopic and laparotomic resection of the endometriosis

\begin{tabular}{|c|c|c|c|c|c|c|}
\hline Procedure & Time (min) & Bleeding (ml) & Blood transfusion & Complication & Complication & Recurrence \\
\hline Hartmann & 285 & 1725 & + & + & Pelvic abscess & + \\
\hline Lap-AR & 170 & 10 & None & None & None & None \\
\hline Lap-LAR & 185 & 10 & None & + & SSI & None \\
\hline Lap-SD & 145 & 10 & None & None & None & None \\
\hline Lap-RHC & 165 & 10 & None & None & None & None \\
\hline Lap-RHC & 135 & 10 & None & None & None & None \\
\hline Lap-LAR & 245 & 50 & None & None & None & None \\
\hline
\end{tabular}

Lap laparoscopic, $A R$ anterior resection, LAR low anterior resection, SD sigmoidectomy, RHC right hemicolectomy, SSI superficial incisional surgical site infection 
Table 3 Clinical data of endometriosis in seven patients with colorectal cancer based on the TNM classification of the Japanese General Rules

\begin{tabular}{|c|c|c|c|c|c|c|c|c|}
\hline Location & Diagnosis & Depth & Type & Size $(\mathrm{mm})$ & $\mathrm{N}$ & M & $\mathrm{H}$ & ly \\
\hline S & GIST & $\mathrm{SI}$ & 2 & 90 & 1 & $1(\mathrm{LM})$ & 0 & 1 \\
\hline Rs & RK & SM & $0-1 l a$ & 15 & 0 & 0 & 0 & 0 \\
\hline Rs & RK & SS & 2 & 36 & 2 & $1(\mathrm{LM})$ & 1 & 1 \\
\hline S & SK & SS & 2 & 33 & 1 & 0 & 1 & 1 \\
\hline A & AK & SM2 $(2000 \mu \mathrm{m})$ & $0-I s p$ & 32 & 1 & 0 & 0 & 0 \\
\hline C & CK & SS & 2 & 36 & 0 & 0 & 0 & 1 \\
\hline Rs & RK & SS & 2 & 48 & 1 & 0 & 0 & 1 \\
\hline \multicolumn{2}{|l|}{ Histology } & \multicolumn{2}{|l|}{ Dissection } & \multicolumn{2}{|l|}{ Number } & \multicolumn{2}{|l|}{ Metastasis } & Stage \\
\hline \multicolumn{2}{|l|}{ mod EM } & \multicolumn{2}{|l|}{ D3 } & \multicolumn{2}{|l|}{9} & \multicolumn{2}{|l|}{1} & IV \\
\hline \multicolumn{2}{|l|}{ wel EM } & \multicolumn{2}{|l|}{ D2 } & \multicolumn{2}{|l|}{12} & \multicolumn{2}{|l|}{0} & 1 \\
\hline \multicolumn{2}{|c|}{ wel mod muc EM } & \multicolumn{2}{|l|}{ D3 } & \multicolumn{2}{|l|}{20} & \multicolumn{2}{|l|}{4} & IV \\
\hline \multicolumn{2}{|c|}{ wel mod EM } & \multicolumn{2}{|l|}{ D3 } & \multicolumn{2}{|l|}{7} & \multicolumn{2}{|l|}{1} & IIla \\
\hline \multicolumn{2}{|c|}{ wel mod pap muc EM } & \multicolumn{2}{|l|}{ D3 } & \multicolumn{2}{|l|}{28} & \multicolumn{2}{|l|}{1} & IIla \\
\hline \multicolumn{2}{|c|}{ wel mod EM } & \multicolumn{2}{|l|}{ D3 } & \multicolumn{2}{|l|}{11} & \multicolumn{2}{|l|}{0} & $\|$ \\
\hline \multicolumn{2}{|c|}{ wel mod EM } & \multicolumn{2}{|l|}{ D3 } & \multicolumn{2}{|l|}{26} & \multicolumn{2}{|l|}{3} & IIla \\
\hline
\end{tabular}

$S$ sigmoid colon, $R$ s rectal sigmoid colon, $A$ ascending colon, $C$ cecum, GIST gastrointestinal stromal tumour, RK rectal cancer, SK sigmoid colon cancer, AK ascending colon cancer, $E M$ endometriosis, SM submucosa, $S S$ sub serosa, $N$ lymph node metastasis, $M$ distant metastasis, $L M$ lung metastasis, $H$ liver metastasis, $l y$ lymphatic invasion, $v$ vascular invasion, wel well differentiated adenocarcinoma, mod moderately differentiated adenocarcinoma, muc mucinous adenocarcinoma

Although lymph node involvement by endometriosis is considered to be uncommon, there are a few reports of endometrial cells in the lymph nodes, despite intestinal endometriosis itself not being considered a malignant disease [9]. Therefore, lymph node dissection is required as well as resection of primary endometrial tissue.

In cases of T4 malignant tumor, intestinal resection with a safety margin and dissection along with a salpingooophorectomy and hysterectomy may be necessary [10]. However, in cases of intestinal endometriosis, which is a benign disease in reproductive women with the full thickness of the intestinal wall with no evidence of malignancy, preserving the uterus and ovary is very important and a laparoscopic approach has great potential as a diagnostic tool [10].

In recent years, laparoscopic surgery for colorectal disease has been appreciated and this technique has been improved; the procedure is also effective for distinguishing intestinal endometriosis from colorectal cancer [11]. Because of the ability of the laparoscope to zoom in and out in the pelvic space, it is possible to diagnose intestinal endometriosis during surgery. Therefore, laparoscopic surgery has great potential to contribute to preserving fertility and reducing invasiveness.

Several studies have shown that laparoscopic colorectal resection for endometriosis is feasible and safe, including a randomized prospective study by Darai and colleagues [12]. We should consider the patient's age and fertility, and complications of the disease. Pelvic endometriosis sometimes involves the intestinal tract and a malignant tumor. When an unexpected pelvic mass lesion is found during surgery, an intraoperative histological examination should be considered for conclusive diagnosis.

In all of our cases, patients were not diagnosed preoperatively. In case 1, preoperative diagnosis was GIST, and it caused severe stenosis of the intestinal tract. In the other cases, preoperative diagnoses were colon cancer; however, they were diagnosed with intestinal endometriosis histologically. In case 7 , we were able to preserve the uterus as rapid diagnosis and laparoscopic observation revealed that there was no invasion by T4 tumor. Furthermore, a previous study described that early diagnosis by intensive endoscopic examination could improve the number of curative colorectal resections [13]. In addition, the use of intraoperative colonoscopy is also very useful in that an adequate cutting line can be obtained by checking mucosal findings.

In our group, we performed laparoscopic surgery for 1433 colorectal cancer cases from November 2003 to June 2010. We consider laparoscopic surgery to be valid for observation of the affected part and pelvic space; therefore, it represents a safe approach for the treatment of intestinal endometriosis or colorectal cancer. Our postoperative morbidity and mortality rate is in accordance with many recent reports [14-17]. Our experience will be related to a suitable intraoperative decision for preserving fertility and preventing excessive surgical stress.

We have performed laparoscopic surgery in combination with intraoperative endoscopy, which discloses the safety 
margin and other masses of the intestine. Especially in the case of laparoscopic low or super-low anterior resection, the edge of the incision line could be determined correctly using this technique in combination with intraoperative endoscopy.

\section{Conclusions}

In conclusion, intestinal endometriosis with colorectal cancer is a relatively rare disease and is difficult to distinguish from T4 cancer. Therefore, we should consider the probability that the cause of bowel obstruction is not T4 but intestinal endometriosis. For surgical treatment, laparoscopic resection of the rectum or colon for intestinal endometriosis can be performed safely and effectively. Therefore, we consider that our laparoscopic approach with intraoperative endoscopy as a standardized technique for this disease will be increasingly indicated.

\section{Abbreviations}

BMl: Body mass index; CT: Computed tomography; GIST: Gastrointestinal stromal tumor; MRI: Magnetic resonance imaging

\section{Acknowledgements}

None.

\section{Funding}

No funding was received for this study.

\section{Availability of data and materials}

Not applicable.

\section{Authors' contributions}

$\mathrm{MI}$ and MY provided clinical data and designed research, and MI, MY, KT, MA, $\mathrm{SM}, \mathrm{HH}, \mathrm{JO}$, and $\mathrm{KU}$ wrote the paper. $\mathrm{HA}$, YE, and $\mathrm{YH}$ collected the pathological data and helped. All authors read and approved the final manuscript.

\section{Ethics approval and consent to participate}

Not applicable.

\section{Consent for publication}

Written informed consent was obtained from the patients for publication of this case report and any accompanying images. A copy of the written consent is available for review by the Editor-in-Chief of this journal.

\section{Competing interests}

The authors declare that they have no competing interests.

\section{Publisher's Note}

Springer Nature remains neutral with regard to jurisdictional claims in published maps and institutional affiliations.

\section{Author details}

'Departments of General and Gastroenterological Surgery, Osaka Medical College, Osaka, Japan. ${ }^{2}$ Cancer Center, Osaka Medical College, Osaka, Japan. ${ }^{3}$ Department of Pathology, Osaka Medical College, Osaka, Japan.

Received: 20 July 2017 Accepted: 5 December 2017

Published online: 30 January 2018

\section{References}

1. Meyers WC, Kelvin FM, Jones RS, et al. Diagnosis and surgical treatment of colonic endometriosis. Arch Surg. 1979;114:169-75.
2. Kratzer G, Salvati E. Collective review of endometriosis of the colon. Am J Surg. 1955;90:866-9.

3. McAfee CHG. Intestinal endometriosis. J Obstet Gynecol Br Emp. 1960;67: 539-59.

4. Wills HJ, Reid GD, Cooper MJ, Tsaltas J, Morgan M, Woods RJ. Bowel resection for severe endometriosis: an Australian series of 177 cases. Aust N Z J Obstet Gynaecol. 2009;49:415-8.

5. Uchiyama S, Haruyama Y, Asada T, Nagaike K, Hotokezaka M, Yorita K, et al. Rectal endometriosis masquerading as dissemination in a patient with recta cancer: report of a case. Surg Today. 2010;40:672-5.

6. Abraham SC, Burgart $L$, Odze RD. Polyps of the large intestine. In: Odze RD, Goldblum JR, Crawford JM, editors. Surgical pathology of the Gl tract, liver, biliary tract, and pancreas. Philadelphia: Elsevier; 2004. p. 327-79.

7. Yantiss RK, Clement PB, Young RH. Endometriosis of the intestinal tract: a study of 44 cases of a disease that may cause diverse challenges in clinical and pathologic evaluation. Am J Surg Pathol. 2001;25:445-54.

8. Kobayashi $Y$, Terauchi F, Toyooka R, Yamamoto $Y$, Moritake $T$, Ogura H, et al. Recurrent endometriosis on the vaginal stump and rectum. J Med Soc Toho. 2004;51(6):360-4.

9. Noël JC, Chapron C, Fayt I, Anaf V. Lymph node involvement and lymphovascular invasion in deep infiltrating rectosigmoid endometriosis. Fertil Steril. 2008:89:1069-72.

10. Kim JS, Hur H, Min BS, Kim H, Sohn SK, Cho CH, et al. Intestinal endometriosis mimicking carcinoma of rectum and sigmoid colon: a report of five cases. Yonsei Med J. 2009;50:732-5.

11. Poon JT, Law WL. Laparoscopic resection for rectal cancer: a review. Ann Surg Oncol. 2009;16:3038-47.

12. Darai E, Dubernard G, Coutant C, Frey C, Rouzier R, Ballester M. Randomized trial of laparoscopically assisted versus open colorectal resection for endometriosis: morbidity, symptoms, quality of life, and fertility. Ann Surg. 2010;251:1018-23.

13. Conzo G, Mauriello C, Gambardella C, Cavallo F, Tartaglia E, Napolitano S, et al. Isolated repeated anastomotic recurrence after sigmoidectomy. World J Gastroenterol. 2014;20:16343-8.

14. Fleshman J, Sargent DJ, Green E, Anvari M, Stryker SJ, Beart Jr RW, et al. Laparoscopic colectomy for cancer is not inferior to open surgery based on 5-year data from the COST Study Group trial. Ann Surg. 2007;246:655-62. discussion 62-4

15. Milsom JW, de Oliveira JO, Trencheva KI, Pandey S, Lee SW, Sonoda T. Long-term outcomes of patients undergoing curative laparoscopic surgery for mid and low rectal cancer. Dis Colon Rectum. 2009;52:1215-22.

16. Redwine DB, Sharpe DR. Laparoscopic segmental resection of the sigmoid colon for endometriosis. J Laparoendosc Surg. 1991;1:217-20.

17. Inomata M, Yasuda K, Shiraishi N, Kitano S. Clinical evidences of laparoscopic versus open surgery for colorectal cancer. Jpn J Clin Oncol. 2009:39:471-7.
Submit your next manuscript to BioMed Central and we will help you at every step:

- We accept pre-submission inquiries

- Our selector tool helps you to find the most relevant journal

- We provide round the clock customer support

- Convenient online submission

- Thorough peer review

- Inclusion in PubMed and all major indexing services

- Maximum visibility for your research

Submit your manuscript at www.biomedcentral.com/submit
Biomed Central 